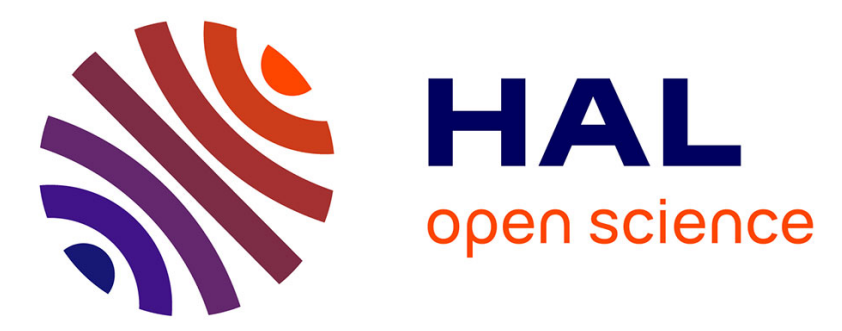

\title{
A quadratic programming based optimisation to manage electric bus fleet charging
}

Adnane Houbbadi, Rochdi Trigui, Serge Pelissier, Eduardo Redondo-Iglesias, Tanguy Bouton

\section{- To cite this version:}

Adnane Houbbadi, Rochdi Trigui, Serge Pelissier, Eduardo Redondo-Iglesias, Tanguy Bouton. A quadratic programming based optimisation to manage electric bus fleet charging. International Journal of Electric and Hybrid Vehicles, 2019, 11 (4), 10.1504/IJEHV.2019.102862 . hal-02149157v2

\section{HAL Id: hal-02149157 \\ https://hal.science/hal-02149157v2}

Submitted on 9 Feb 2021

HAL is a multi-disciplinary open access archive for the deposit and dissemination of scientific research documents, whether they are published or not. The documents may come from teaching and research institutions in France or abroad, or from public or private research centers.
L'archive ouverte pluridisciplinaire HAL, est destinée au dépôt et à la diffusion de documents scientifiques de niveau recherche, publiés ou non, émanant des établissements d'enseignement et de recherche français ou étrangers, des laboratoires publics ou privés. 


\title{
A quadratic programming based optimisation to manage electric bus fleet charging
}

\section{Adnane Houbbadi*, Rochdi Trigui, Serge Pelissier and Eduardo Redondo-Iglesias}

\author{
Univ Lyon, \\ IFSTTAR, AME, ECO7, \\ F-69675, Lyon, France \\ Email: adnane.houbbadi@ifsttar.fr \\ Email: rochdi.trigui@ifsttar.fr \\ Email: serge.pelissier@ifsttar.fr \\ Email: eduardo.redondo@ifsttar.fr \\ ${ }^{*}$ Corresponding author

\section{Tanguy Bouton} \\ TRANSDEV Group Headquarters, \\ 3 Allee de Grenelle, \\ 92442 Issy Les Moulineaux, France \\ Email: tanguy.bouton@transdev.com
}

\begin{abstract}
The use of electric buses (EBs) is expected to increase significantly in the coming years. Uncontrolled charging of EBs can affect not only the power grid (grid instability, harmonic pollution) but also the operating cost. This paper introduces an optimal charging strategy based on charging schedule planning and modulation of charging power for a fleet of electrical-powered buses. The optimal charging strategy allows minimising the charging cost as well as the load power variations using quadratic programming. The proposed quadratic programming can significantly reduce the computation time and simultaneously handle a large bus fleet. First results indicate a significant reduction in customer energy bills while avoiding potential penalties due to peak loads.
\end{abstract}

Keywords: electric bus fleet; optimisation; quadratic programming; charging infrastructure; electric vehicle supply equipment.

Reference to this paper should be made as follows: Houbbadi, A., Trigui, R., Pelissier, S., Redondo-Iglesias, E. and Bouton, T. (xxxx) 'A quadratic programming based optimisation to manage electric bus fleet charging', Int. J. Electric and Hybrid Vehicles, Vol. x, No. x, pp.xxx-xxx.

Biographical notes: Adnane Houbbadi received his Master's degree in Mechatronics and Energy Research and Development from the University of Strasbourg in 2015. He received the advanced Master in Renewable Energy Projects and Production from Arts et Métiers ParisTech in 2016. In 2017, he joined IFSTTAR as a PhD student. His work is in collaboration with TRANSDEV and focuses on the optimisation of an electric bus fleet charging. 
Rochdi Trigui received his $\mathrm{PhD}$ in Electrical Engineering in 1997 from the Polytechnic National Institute of Lorraine. He then worked for one year as an Associate Researcher at PSA Peugeot Citroën. Since 1998, he is Full Researcher (senior since 2012) in IFSTTAR (former INRETS) in the field of modelling and energy management of electric and hybrid vehicles. He is now Deputy Head of AME Department of IFSTTAR and was co-chair of IEEE VPPC 2010.

Serge Pelissier received his $\mathrm{PhD}$ in Electrical Engineering from the Institut National Polytechnique Grenoble, he first became Associate Professor and then Professor at the University of St. Etienne. In 2007, he joined INRETS (IFSTTAR since 2011). His work focuses on modelling, characterisation and ageing of batteries in automotive applications.

Eduardo Redondo-Iglesias is in charge of the battery test equipments in IFSTTAR. In 2017, he received his PhD in Electrical Engineering from the University of Lyon (France). His research activities are electrical modelling and characterisation of batteries and their ageing for transportation applications.

Tanguy Bouton graduated two Master 2. First one at La Sorbonne University in International Business Consulting, second one at Paris Est University, specialised in Urbanism and Urban Transportation. He worked in different manufacturing companies in transports before becoming manager of Energy Transformation Business at TRANSDEV Group Headquarters.

\section{Introduction}

The transport sector in Europe is responsible for significant air pollutant emissions, which became a major public health issue. The European Union (EU) has committed to cut its emissions of greenhouse gases (GHG) to $40 \%$ below 1990 levels by 2030 (European Commission, 2018).

Electro-mobility will better address the challenges associated to urban transport with high energy efficiency and low GHG emissions. Therefore, the use of electric buses (EBs) is a key aspect to achieve these objectives and a way to reduce the GHG emissions. However, managing electro-mobility in local public transport is not an easy task. A large-scale deployment of EBs will have a great impact on the electrical system, generating network congestion problems and requiring more electricity generation to cover the peak demand (Dietmannsberger, 2017).

On the other hand, over cost of EB purchase compared to thermal buses should be paid back by reducing the operation cost that is sensitive to electricity price.

To optimise the EB fleet charging, a quadratic programming optimisation has been developed in this work. The capability of modulating and scheduling the charging power allows then adopting smart strategies in order to reduce the charging cost and the load power variations with regard to technical constraints including maximum power limits.

This paper is organised as follows. In Section 2, we introduce the charging infrastructure and the electrical power system. In Section 3, we discuss our proposed approach for smart charging of EBs. Then, we present and discuss our results for a case study with different operating scenarios. In Section 7, we draw some conclusions and present some future work. 


\section{Infrastructure and charging system}

\subsection{Electric vehicle supply equipment}

An electric vehicle charging infrastructure, also called electric vehicle supply equipment (EVSE), is an infrastructure that provides electric energy, energy conversion, monitoring and safety functionality according to international standards from the International Electrotechnical Commission (International Electrotechnical Commission, 2017).

In this paper, we only deal with heavy vehicles (electric buses) that are connected to the main power grid through an external dedicated off-board AC/DC and DC/DC converter that supplies DC power directly to the EB's battery. Control and protection functions and the vehicle charging cable are installed permanently in the installation. The considered charging infrastructure is equipped with a power transformer, which lowers voltage and supplies the conversion system. The conversion system consists of an $\mathrm{AC} / \mathrm{DC}$ converter and a $\mathrm{DC} / \mathrm{DC}$ charger, which is dedicated to a charging point. The generalised system architecture is presented in Figure 1.

Figure 1 System architecture of the EVSE (see online version for colours)

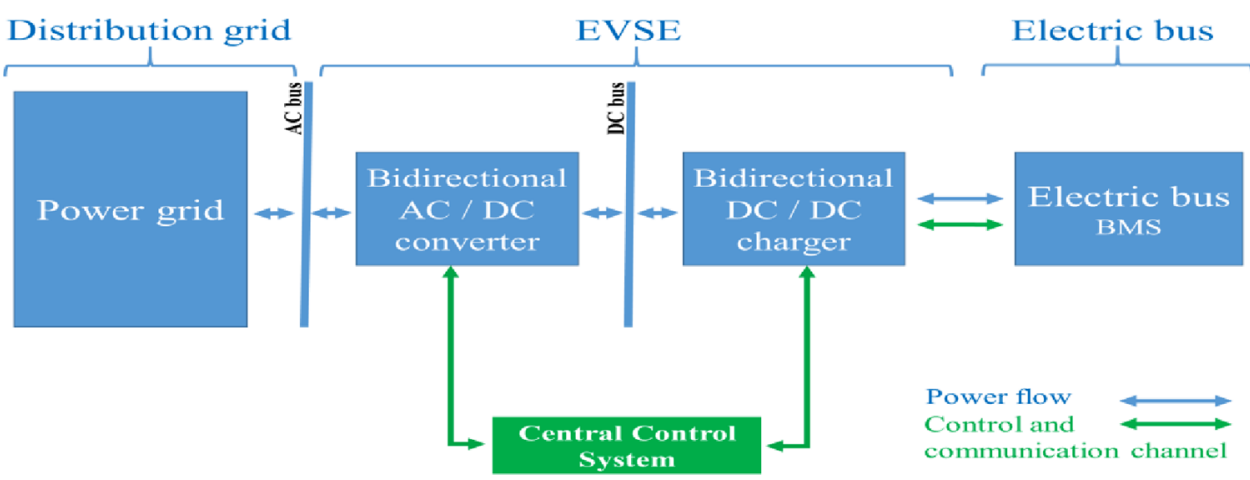

The DC/DC charger is managed by a central control system. This controller checks the conversion equipment and carries out the communication with the EB to perform the charging according to a standardised communication protocol (PLC) EN 61851-23 (International Electrotechnical Commission, 2017). A standard socket type Combo 2 CCS makes the hardware connection between the EB and the charger.

During the charging process, several information needed are exchanged in PLC format between the bus and the charger (International Electrotechnical Commission, 2017).

\subsection{Communication and charging protocol via CCS/COMBO}

The International Standard IEC 61851-1 defines 4 charging modes for light EV: modes 1, 2, 3 are for AC charging with slow and fast charging up to $43 \mathrm{~kW}$, while charging of EBs is governed by mode 4 , which uses DC power charging beyond $50 \mathrm{~kW}$. Currently, there exists two types of DC charging systems: the CCS2 (Combined Charging System) COMBO used on this paper and ChaDeMo charger (Lewandowski et al., 2012). The most 
common charging method employed for charging lithium-ion batteries is the constant current/constant voltage $(\mathrm{CC} / \mathrm{CV})$ charging algorithm.

During the $\mathrm{CC}$ sequence, a constant current is applied to charge the battery until the battery voltage reaches a maximal value defined as the cut-off voltage at which $\mathrm{CV}$ begins. CV charging is used to limit the current and thus prevent the battery from overcharge. The charging process stops when the charging current reaches a small value. Figure 2 shows the charging profile of the CC/CV (Redondo-Iglesias et al., 2018). The $\mathrm{CC}$ and $\mathrm{CV}$ phase duration depends on initial state-of-charge $(\mathrm{SoC})$ and on charging power. The $\mathrm{CV}$ phase lasts about $20 \mathrm{~min}$ for a $1 \mathrm{C}$ charging rate for lithium iron phosphate cells (Eddahech et al., 2014) and takes even less time at low charging rates.

Figure 2 Charging profile the $\mathrm{CC} / \mathrm{CV}$ charging algorithm for a lithium-ion battery (see online version for colours)

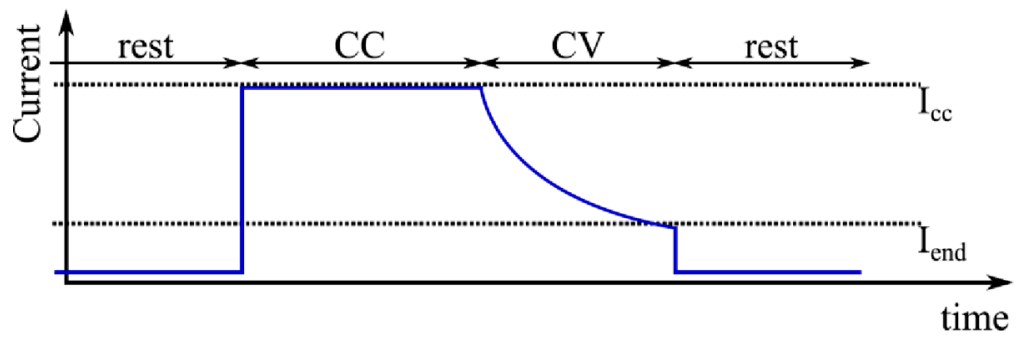

Source: Redondo-Iglesias et al. (2018)

During the CCS 2 COMBO protocol charging, a master-slave configuration is used (battery being the 'master' and charger the 'slave') to share information and set the maximum charging current limit based on the power rating of the EV and the charger.

In case of 'smart charging', the 'slave-charger' has to be able to modulate the power with a maximum limit remaining below the one requested by the 'master-battery'.

Figure 3. Charging current request via CCS 2 (see online version for colours)

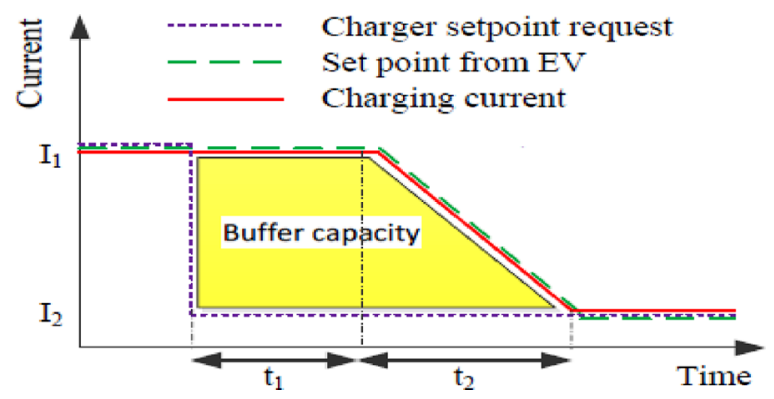

Source: Mouli et al. (2016)

The charger and battery continuously negotiate and set a charging current setpoint command every $200 \mathrm{~ms}$ based on the charging algorithm of the battery management system, which is any electronic system that manages the cell or battery pack charging.

The charger can make a new setpoint request to change the current and battery has to accept or decline this request. If the request is accepted, battery changes the current set 
point and the charger can charge the battery based on the negotiated set point as shown in Figure 3 (Mouli et al., 2016). For the period $\left(t_{1}+t_{2}\right)$, a buffer capacity is required either to store the energy from the grid or to provide the energy required.

\section{Methodology and system modelling}

This part introduces a methodological approach (Figure 4) to develop an optimal charging strategy for a fleet of EBs in urban transport. This approach uses quadratic programming to search for optimal plans according to the objective function (by minimising the charging cost as well as the load variations) while taking into account the technical constraints (actual operating constraints, constraints of the power grid and the charging station). The optimisation methodology has been implemented in the Matlab/Simulink environment. During the smart charging process, information on the operating bus constraints (number of buses, initial SoC, the target $\mathrm{SoC}$, the amount of energy required, arrival and departure time, maintenance period) has to be filled.

Other constraints related to the charging infrastructure and power grid are added. For instance, the subscribed power, the maximum charging power delivered by the charger and the electricity cost. The optimisation algorithm attributes an optimal charging power profile for each bus depending on objectives and respecting these constraints.

Figure 4 Smart charging methodology (see online version for colours)

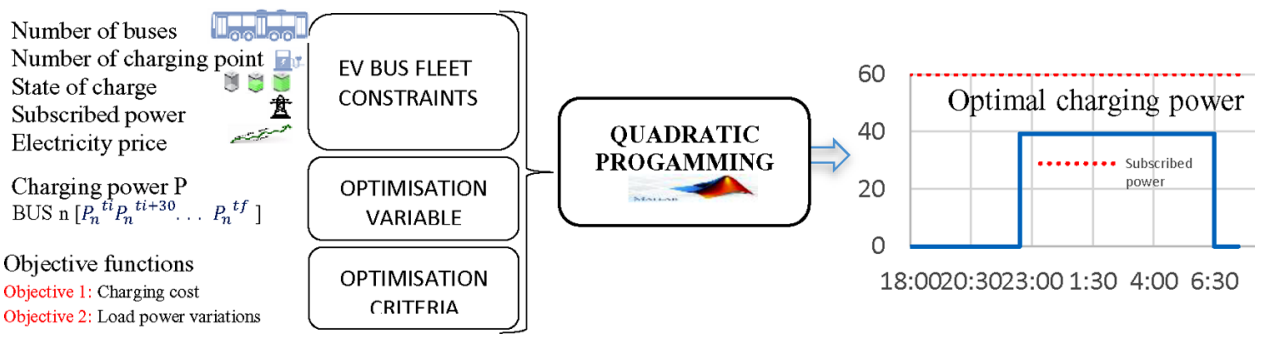

Once the optimisation is finished, the optimal charging power profile is applied to a converter model that represents the charger and a battery model. The aim is to check if the battery received enough energy and if its temperature is not too high. These models are presented in Figure 5.

Figure 5 Converter and battery models

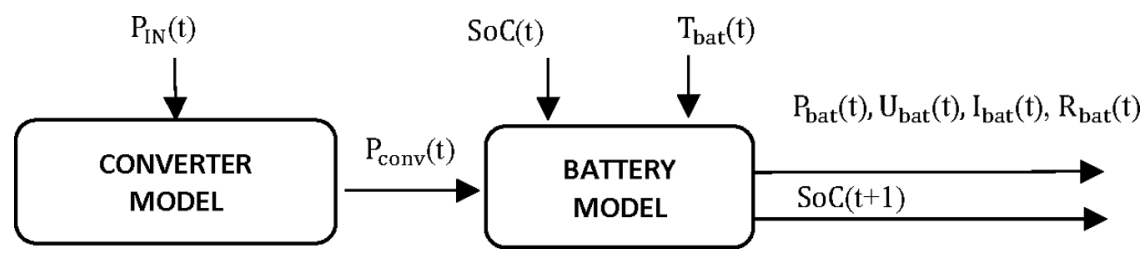




\subsection{Converter model}

The efficiency of an EV charger depends on the efficiency of various internal components. Electrical power comes from the grid and is converted several times, from the AC supply to the DC/DC converter and from the DC/DC converter to the battery, as we presented in Figure 1.

To stay in an acceptable simulation time, we used some experimental results of a quick charger test efficiency as converter model to represent the AC/DC and the DC/DC converter power losses (Genovese et al., 2015). These data represent the average charger efficiency during the charging tests for different charging power.

In a first approach, until we develop a specific converter model, we will use five charger efficiency values corresponding to five charging power ranges based on the experimental results.

\subsection{Battery model}

Several equivalent electrical models are proposed in the literature (Mousavi and Nikdel, 2014). The simplest model to describe the behaviour of an accumulator is the $\mathrm{OCV}+\mathrm{R}$ model, which associates a voltage source and a resistance. This model is very effective to describe phenomena in a simplified way. However, it does not represent the dynamic behaviour of a battery. More complex models consist of a voltage source in series with different dipoles. Different evolutions of the $\mathrm{OCV}+\mathrm{R}$ model are possible through the addition of one or several capacitors $\mathrm{C}$ or a CPE ('constant phase element') to represent the dynamic behaviour of the battery (Long Lam et al., 2011). However, it appears for the purpose of this work that an OCV $+\mathrm{R}$ model provides the necessary accuracy with very short computation time.

The battery model used in this work contains a previously developed electric model based on VEHLIB (Trigui et al., 2004) which is a systemic vehicle simulation software, developed by IFSTTAR-LTE. The simplified electrical model is shown in Figure 6.

Figure 6 Battery equivalent circuit

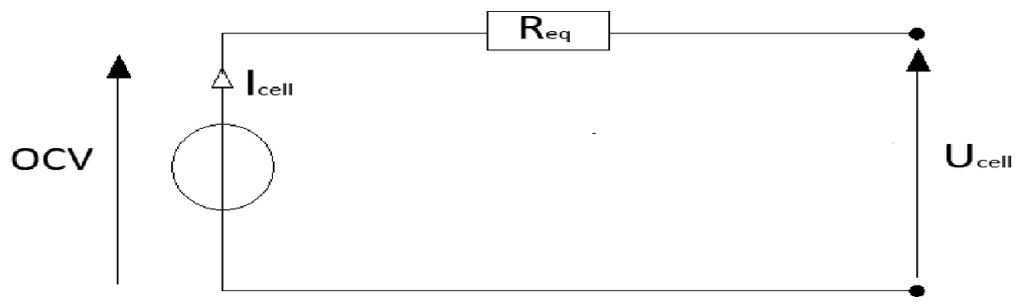

The equivalent electric circuit equation:

$$
U_{\text {cell }}=\mathrm{OCV}-R_{e q} \times I_{\text {cell }}
$$

This model implements an ideal voltage source OCV that represents the open circuit voltage of the battery, and a resistor $R_{e q}$ that includes an ohmic resistance, double layer and diffusion. Resistance and $\mathrm{OCV}$ are a function of SoC and temperature. $I_{\text {cell }}$ is the battery current with a positive value when discharging and a negative value when charging. $U_{\text {cell }}$ is the battery voltage. 


\section{Problem formulation}

\subsection{Quadratic programming optimisation}

As part of this work, an optimisation methodology to identify the optimal charging strategy for a fleet of EBs has been developed. The methodological approach is based on both charging scheduling and power modulation in order to minimise the charging cost as well as the load power variations by taking into account operating constraints.

Several methods for smart charging of electric vehicles were compared through an extensive literature review (Hu et al., 2016). Hu et al. (2016) have compared nine optimisation methods used for smart charging of electric vehicles with different objectives. These methods include linear programming, quadratic programming, dynamic programming, mixed integer linear programming, mixed integer nonlinear programming, stochastic programming, heuristics and metaheuristics.

In terms of computational time, the linear programming (LP) is generally the fastest one. However, in terms of applicability, it cannot be used in this problem because of the non linearity of the objective function. A quadratic programming $(\mathrm{QP})$ was compared to the linear programming (LP) (Sundstrom and Binding, 2012) in order to minimise the total charging cost of 50 vehicles. Results showed that the calculation time using the QP is then increased compared to the one using LP and showed that the gain in accuracy of the results between using LP and QP is minor. Clement-Nyns et al. (2010) indicated that the computational time for dynamic programming is higher compared to QP. The study in (Sousa et al., 2012) indicated that the computational time of non-linear programming is highly dependent of the number of EVs. Stochastic programming (Clement-Nyns et al., 2010), heuristics and metaheuristics (Sousa et al., 2014), robust and model predictive control (Di Giorgio et al., 2014), particle swarm optimisation (Soares et al., 2013) are generally longer and are more suitable to complex problem difficult to implement.

The choice of the optimisation algorithm strongly depends on the form of the objective functions. In this paper, regarding the quadratic form of our objective function with linear constraints, QP has been selected for dealing with the optimisation problem expecting a fast calculation time and sufficiently accurate results.

\subsection{Pre-optimisation process}

Before the optimisation process, one need to determine the amount of energy required to reach the target $\mathrm{SoC}$ of the battery. We use the battery model with different charging power at different $\mathrm{SoC}$ values to determine an average charging efficiency that will be used during the optimisation.

Different charging power was applied over $30 \mathrm{~min}$ as an input in the battery model. The battery efficiency represent the average value for different initial $\mathrm{SoC}$ values ranging from $10 \%$ to $90 \%$. The results are reported in Table 1 .

Different charging power was applied in Genovese et al. (2015) for different initial SoC values to determine the charger efficiency. The results are reported in Table 2. 
Table 1 Battery model voltage and efficiency

\begin{tabular}{lc}
\hline Charging power & Battery efficiency $(\%)$ \\
\hline $10 \mathrm{~kW}$ & 99.7 \\
$20 \mathrm{~kW}$ & 99.4 \\
$30 \mathrm{~kW}$ & 99.2 \\
$40 \mathrm{~kW}$ & 99 \\
$50 \mathrm{~kW}$ & 98.7 \\
$60 \mathrm{~kW}$ & 98.5 \\
\hline Average value & 99 \\
\hline
\end{tabular}

Table 2 EB charger efficiency

\begin{tabular}{lc}
\hline Charging power & Charger efficiency $(\%)$ \\
\hline $3 \mathrm{~kW}$ & 86 \\
$16 \mathrm{~kW}$ & 91.6 \\
$22 \mathrm{~kW}$ & 92.2 \\
$43 \mathrm{~kW}$ & 92.6 \\
$50 \mathrm{~kW}$ & 92.6 \\
\hline Average value & 91 \\
\hline
\end{tabular}

Source: Genovese et al. (2015)

\subsection{Optimisation design variable}

The quadratic optimisation problem refers to the optimisation of a quadratic objective function of several variables. In this work, the optimisation variable represents the charging power $\boldsymbol{P}$ of the bus fleet in an $(n \times m)$ matrix:

$$
\boldsymbol{P}=\left(\begin{array}{cccc}
p_{1,1} & p_{1,2} & \cdots & p_{1, m} \\
p_{2,1} & p_{2,2} & \cdots & p_{2, m} \\
\cdot & \cdot & \cdots & \cdot \\
\cdot & \cdot & \cdots & \cdot \\
p_{n, 1} & p_{n, 2} & \cdots & p_{n, m}
\end{array}\right)=\left(\boldsymbol{p}_{i, j}\right) \mid\left\{\begin{array}{l}
1 \leq i \leq n \\
1 \leq j \leq m
\end{array}\right\}
$$

where $n$ is the total number of EB and $m$ the number of time slots, $\boldsymbol{p}_{\boldsymbol{i}, \boldsymbol{j}}$ is the charging power for EB $i$ during a time slot $j$.

\subsection{Objective functions}

The aim is to minimise the overall cost of charging as well as the load power variations. This problem can be formulated as a follow:

$$
f_{\text {objective }}=f_{\text {cost }}+f_{\text {load }}
$$


The charging cost is expressed as a linear function:

$$
f_{\text {cost }}=\sum_{i=1}^{n} \sum_{j=1}^{m} \boldsymbol{p}_{i, j} \times \Delta t \times c_{j}
$$

where $\boldsymbol{p}_{i, j}$ denotes the charging power of EB $i$ during a time slot $j(\mathrm{~kW}), \Delta t$ represents the time-slot of $30 \mathrm{~min}(\mathrm{~h}), c_{j}$ the electricity price during a time slot $j$ $(€ / \mathrm{kWh})$

The load power variations is expressed as a quadratic function:

$$
f_{\text {load }}=\sum_{i=1}^{n} \sum_{j=1}^{m} \boldsymbol{p}_{i, j}{ }^{2}
$$

The squared values of the charging power are used to penalise load variations and promote a smooth average load demand.

The total weighted objective function

We normalised these two functions to introduce a weighting factor $\alpha$ that would tend to prioritise the charging cost. Thus, this problem can be formulated as a quadratic program:

$$
f_{\text {objective }}=\sum_{i=1}^{n} \sum_{j=1}^{m} \boldsymbol{p}_{i, j} \times \Delta t \times c_{j}+\alpha \times \boldsymbol{p}_{i, j}{ }^{2}
$$

\subsection{Intermediate variables}

During the quadratic optimisation problem, the optimisation variable $P$ is subjected to several constraints. These can take various forms such as bound constraints, equality and inequality constraints. The constraints influence in one case all elements of the optimisation variable matrix $\boldsymbol{P}$ and in other case, they are applied to certain rows and columns of the matrix $\boldsymbol{P}$. Therefore, we introduced two intermediate variables that represent a submatrix of the optimisation variable $\boldsymbol{P}$.

We defined a submatrix $\boldsymbol{P}_{\{j\}}$ that represents the charging power for all the buses during a time slot $j$ :

$$
\boldsymbol{P}_{\{j\}}=\left(\begin{array}{c}
p_{1, j} \\
p_{2, j} \\
\cdot \\
\cdot \\
p_{n, j}
\end{array}\right) \quad\{1 \leq j \leq m\}
$$

We defined a submatrix $\boldsymbol{P}_{\{i\}}$ that represents the charging power of a bus $i$ during the total time slots:

$$
\boldsymbol{P}_{\{i\}}=\left(p_{i, 1} p_{i, 2} \ldots \ldots \ldots p_{i, m}\right) \quad\{1 \leq i \leq n\}
$$




\subsection{Constraints and variable boundaries}

During the optimisation, the maximum charging power for each individual DC/DC charger imposes a bound constraint to all elements of the optimisation variable $\boldsymbol{P}$

$$
0 \leq \boldsymbol{p}_{i, j} \leq p_{\max } \quad\left\{\begin{array}{c}
1 \leq i \leq n \\
1 \leq j \leq m
\end{array}\right\}
$$

The charging infrastructure subscribed power imposes an inequality constraint to the submatrix $\boldsymbol{P}_{\{j\}}$ (10). A denotes an all-ones $(1 \times n)$ matrix, $\boldsymbol{P}_{\{j\}}$ is an $(n \times 1)$ refers to the charging power for all the buses during a time slot $j$ :

$$
A \times \boldsymbol{P}_{\{j\}} \leq p_{\text {subscribed }}
$$

The operating bus constraints (the bus arrival and departure time) impose an equality constraint to the submatrix $\boldsymbol{P}_{\{i\}}$

$$
B \times \boldsymbol{P}_{\{i\}}{ }^{T}=0
$$

$B$ denotes an $(1 \times m)$ matrix that will take 0 between the bus arrival and departure time and 1 in the other case, $\boldsymbol{P}_{\{i\}}{ }^{T}$ (the transpose of the matrix $\boldsymbol{P}_{\{i\}}$ ) is an $(m \times 1)$ matrix that represents the charging power of a bus $i$ during the total time slots.

The operating bus constraint (number of $\mathrm{km}$ ) will define the final battery $\mathrm{SoC}$ to reach. It also impose the amount of energy required to reach the target $\mathrm{SoC}$ as an equality constraint to the submatrix $\boldsymbol{P}_{\{i\}}$

$$
C \times P_{\{i\}}{ }^{T}=\frac{\left(\mathrm{SoC}_{\text {final }}-\mathrm{SoC}_{\text {initial }}\right) \times \mathrm{Bat}_{\text {capacity }} \times \mathrm{OCV}}{100 \times \Delta T \times \eta_{c h} \times \eta_{\text {bat }}}
$$

where $C$ denotes an all-ones $(1 \times m)$ matrix, $\boldsymbol{P}_{\{i\}}{ }^{T}$ is an $(m \times 1)$ matrix that represents the charging power of a bus $i$ during the total time slots (W), $\Delta T$ the time-slot of 30 min ( $\mathrm{h}$ ), and $\mathrm{Bat}_{\text {Capacity }}$ denotes the total battery capacity (Ah), $\eta_{c h}$ is the average charger efficiency (\%), $\eta_{\text {bat }}$ is the average battery efficiency (\%), OCV is the open-circuit voltage of the battery (Volt). The average values are from Tables 1 and 2.

\section{Case study}

A case study was performed to simulate the smart charging of an EB fleet. The considered station is capable of supporting the simultaneous recharge of 10 EBs. The schematic of the setup is shown in Figure 7. The EBs will operate an existing conventional bus line. An AC/DC converter draws the power request from the grid to the DC/DC converter. Each DC/DC converter powers a charger where standard Combo CC2 is used.

The EB fleet is charged only at the depot within a period ranging from $6: 00 \mathrm{pm}$ to 7:30 am. Because of the large time range during charging (more than $12 \mathrm{~h}$ between the starting time and the end time), we chose a time step $\Delta t$ of $30 \mathrm{~min}$ that gives a total of $m=27$ time slots, which results in a reasonable sized search space. 
Figure 7 Charging infrastructure (see online version for colours)

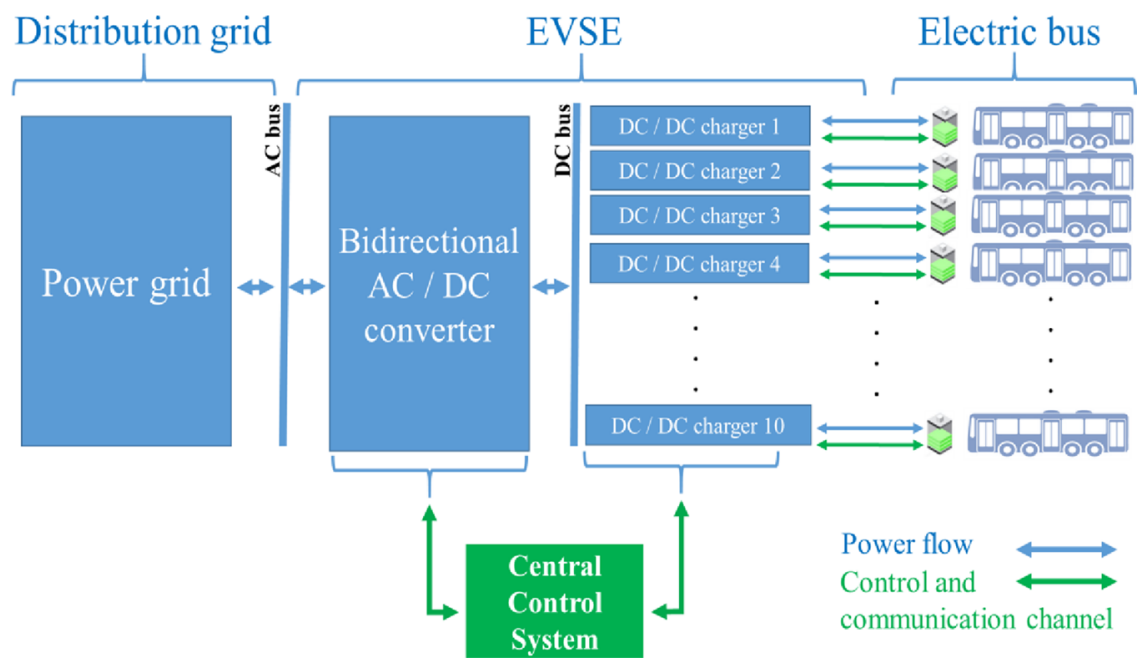

Each bus of the EB fleet arrives to the depot at a different time with different initial SoC. The ambient and initial battery temperatures are fixed to $25^{\circ} \mathrm{C}$. These data correspond to the input of our optimisation model.

We chose variable electricity costs in order to analyse the behaviour of our optimisation algorithm towards a dynamic charging scenario. The high cost period is from $6: 00 \mathrm{pm}$ to $8: 00 \mathrm{pm}$ and $6: 30$ am to $7: 30 \mathrm{am}$, whereas the low-cost period starts from 8:00 pm to 6:30am. The simulation parameters are shown in Table 3 .

Each charging point can provide up to $60 \mathrm{~kW}$ for charging a bus and the maximum subscribed power represent the sum of all the maximum power delivered by each charging point.

Table 3 Simulation parameters

\begin{tabular}{lc}
\hline Parameters & Value \\
\hline Number of buses fleet & {$[1 \rightarrow 10]$} \\
Number of simulated days & 1 \\
Charging time & From 18:00 to $7: 30$ \\
Charging slot & $30 \mathrm{~min}$ \\
Charging power & {$[0 \mathrm{~kW} \rightarrow 60 \mathrm{~kW}]$} \\
Number of charging time slots & 27 \\
Initial state of charge & {$[10 \% \rightarrow 50 \%]$} \\
Initial battery temperature & $25^{\circ} \mathrm{C}$ \\
Fixed outside temperature & $25^{\circ} \mathrm{C}$ \\
Weighting coefficient & 0.7 \\
Electricity costs & \\
18:00 - 22:30 | 06:30 - 07:30 & $0.049 € / \mathrm{kWh}$ \\
$22: 30-06: 30$ & $0.036 € / \mathrm{kWh}$ \\
\hline
\end{tabular}


The battery cell characteristics and battery pack specifications are shown in Tables 4 and 5 .

Table 4 Battery cell specifications

\begin{tabular}{lc}
\hline Parameters & Value \\
\hline Battery type & LFP \\
Nominal energy/capacity & $64 \mathrm{Wh} / 20 \mathrm{Ah}$ \\
Nominal voltage & $3.2 \mathrm{~V}$ \\
\hline
\end{tabular}

Table 5 Battery pack specifications

\begin{tabular}{lc}
\hline Parameters & Value \\
\hline Nominal energy/capacity & $311 \mathrm{kWh} / 540 \mathrm{Ah}$ \\
Nominal voltage & $576 \mathrm{~V}$ \\
\hline
\end{tabular}

\section{Results and analysis}

\subsection{Optimisation of the bus fleet charging using a specific scenario}

We are going to optimise one single EB with specific operating constraints to see if the optimisation algorithm trends towards optimal values. First, information on the operating bus constraints (number of buses, initial SoC, arrival and departure time, the length of the trip ( $\mathrm{km})$, maintenance time) and EVSE constraints has to be filled. The optimisation algorithm attributes the optimal charging power for the EB fleet to minimise the charging cost as well as the load power variations while respecting these constraints. Once the optimisation is finished, the optimal charging power goes through a converter model that represents the charger and a battery model in order to check if the battery received enough energy and if its temperature is not too high.

The results of quadratic optimisation in Figure 8 show that the optimal charging power agrees perfectly with the variation of the electricity costs while respecting the subscribed power. The used weighting factor $(\alpha=0.7)$ tend to charge the EB during all the low-cost period with an average load demand of $40 \mathrm{~kW}$. The optimisation with a larger size of bus fleets (10 EBs) with the same constraints has been performed. It shows the same results and follows the same trend as one single EB.

We present an example of one optimal solution among others with a weighting factor $(\alpha=0)$ in Figure 9. The use of this weighting factor makes the objective function totally dependent on the charging cost. The result shows that the algorithm charges during the low cost period without considering the mean power. The fact of disabling the quadratic part of the objective function makes that the only criterion is electricity cost. Other solutions are equivalent to this one in terms of electricity cost, for example, the constant power profile shown in Figure 8.

The optimisation parameters and constraints are shown in Table 6. 
Figure 8 Optimal charging schedules scenario $1(\alpha=0.7)$ (see online version for colours)
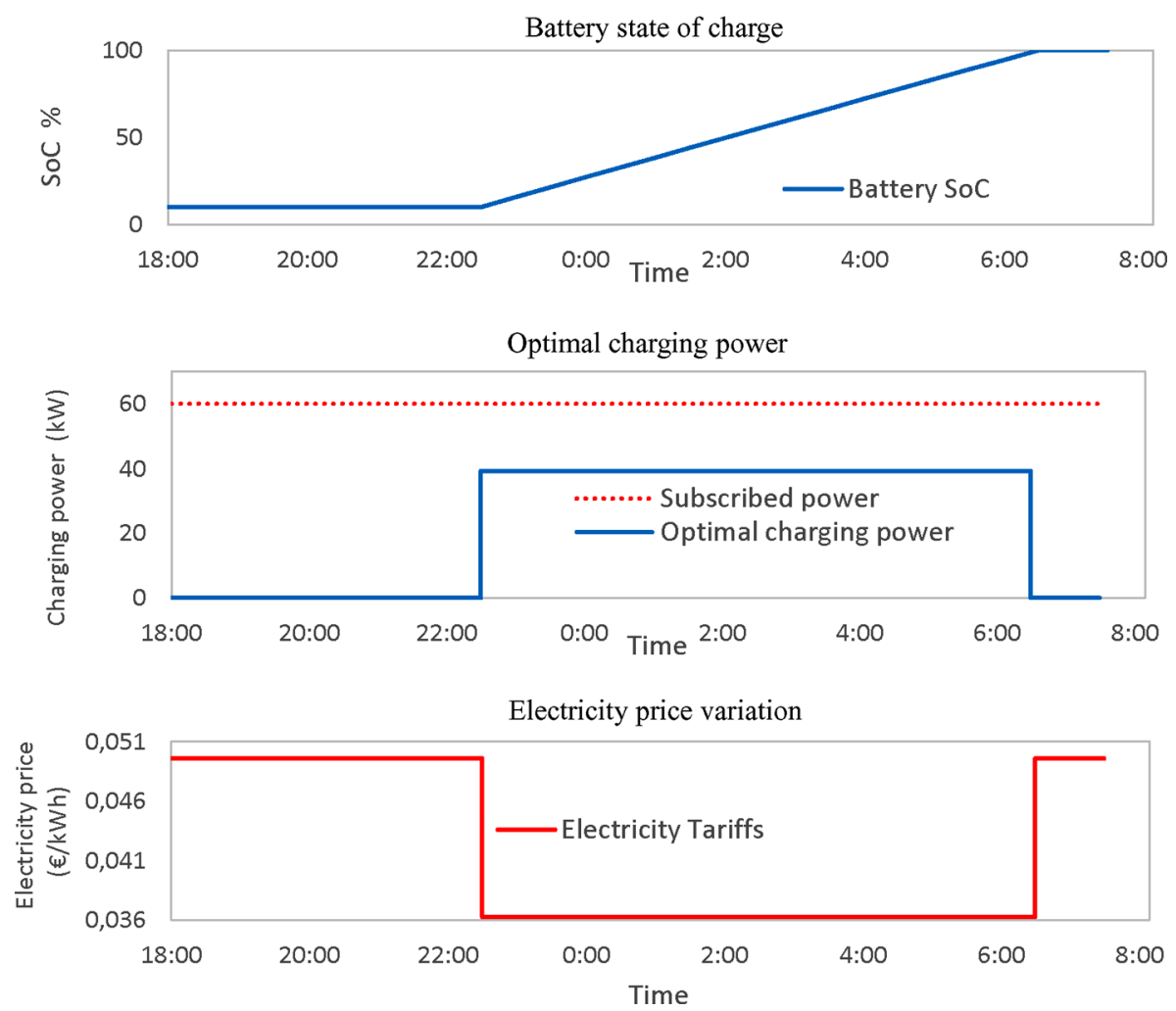

Table 6 Scenario 1: optimisation constraints

\begin{tabular}{lc}
\hline Smart charging & Operating constraints scenarios \\
\hline Number of bus fleet & 1 \\
Initial SoC & $10 \%$ \\
Arrival time & $18: 00$ \\
Departure time & $07: 30$ \\
Length of the trip & $200 \mathrm{~km}$ \\
Target SoC & $100 \% \mathrm{SoC}$ \\
Maximum charging power per bus & $60 \mathrm{~kW}$ \\
Subscribed power (total maximum power) & $60 \mathrm{~kW}$ \\
\hline
\end{tabular}

\subsection{Optimisation of the bus fleet charging using different scenarios}

In scenario No. 2, we are going to optimise a fleet of two buses by adding some variant operating constraints to see if the optimisation algorithm will converge while respecting all the operating constraints presented in Table 7. The weighting factor was fixed to $(\alpha=0.7)$. 
Figure 9 Optimal charging schedules scenario $1(\alpha=0)$ (see online version for colours)
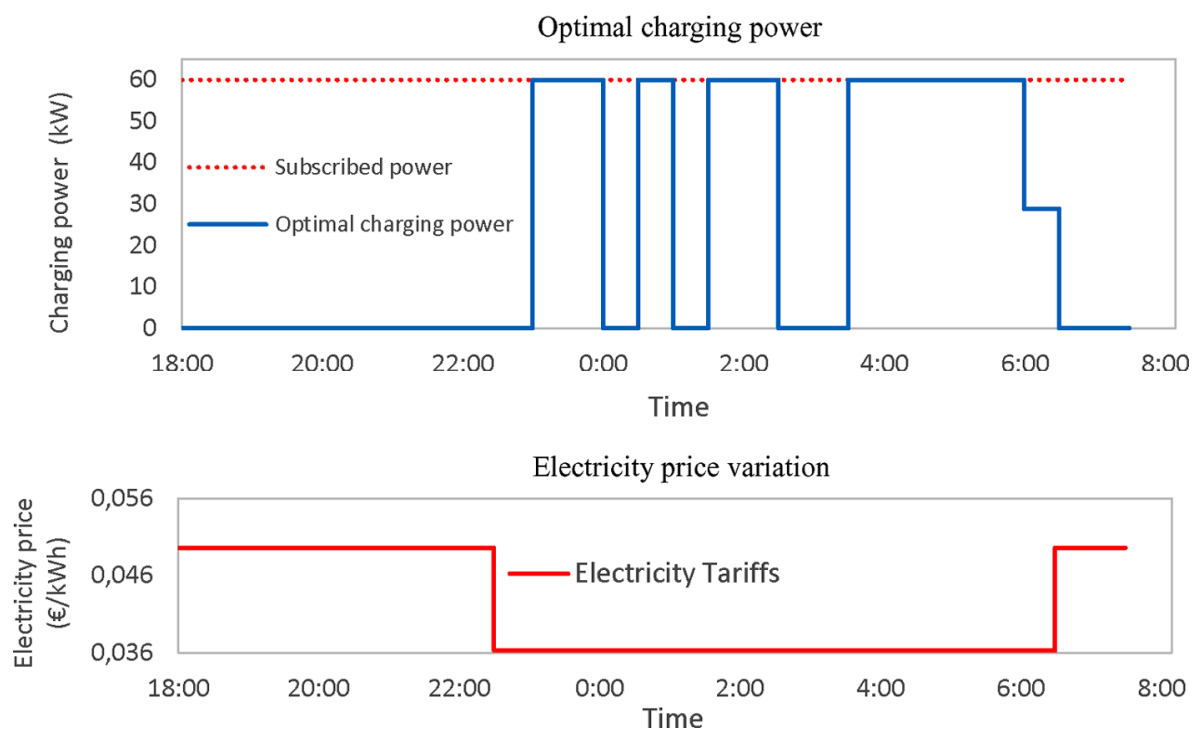

Table $7 \quad$ Scenario 2: Optimisation constraints

\begin{tabular}{lcc}
\hline & \multicolumn{2}{c}{ Number of bus fleet } \\
\cline { 2 - 3 } Smart charging & $E B 1$ & $E B 2$ \\
\hline Initial SoC & $20 \%$ & $10 \%$ \\
Arrival time & $18: 00$ & $23: 00$ \\
Departure time & $07: 30$ & $05: 00$ \\
Length of the trip & $100 \mathrm{~km}$ & $200 \mathrm{~km}$ \\
Target SoC & $50 \%$ & $100 \%$ \\
Maximum charging power per bus & $60 \mathrm{~kW}$ & $60 \mathrm{~kW}$ \\
Subscribed power (total maximum power) & \multicolumn{2}{c}{$60 \mathrm{~kW}$} \\
\hline
\end{tabular}

The results of quadratic optimisation in Figure 10 show that the optimal charging power charges the EB 2 during all the possible charging period (when the bus is available) with an average power of $50 \mathrm{~kW}$. Once the EB $\mathbf{2}$ charging period is filled, the algorithm set up the EB 1 charging period in a way to avoid exceeding the subscribed power during the low-cost period.

In scenario No. 3, we are going to optimise 4 EBs by adding some operating constraints quite similar to an existing conventional bus line while imposing a subscribed power of $100 \mathrm{~kW}$. The weighting factor was fixed to $(\alpha=0.7)$.

The results of quadratic optimisation in Figure 11 show that the optimal charging power starts to charge the most constrained bus which is the EB $\mathbf{4}$, then the algorithm try to fill the other EBs charging profile in a way to avoid exceeding the subscribed power during the low-cost period. Subject to several constraints, once the algorithm filled all the low-cost period, it has been forced to charge during the high cost period 
otherwise the power would exceed the subscribed power as we can see for EB 1, EB 2, and EB 3.

Figure 10 Optimal charging schedules scenario 2 (see online version for colours)
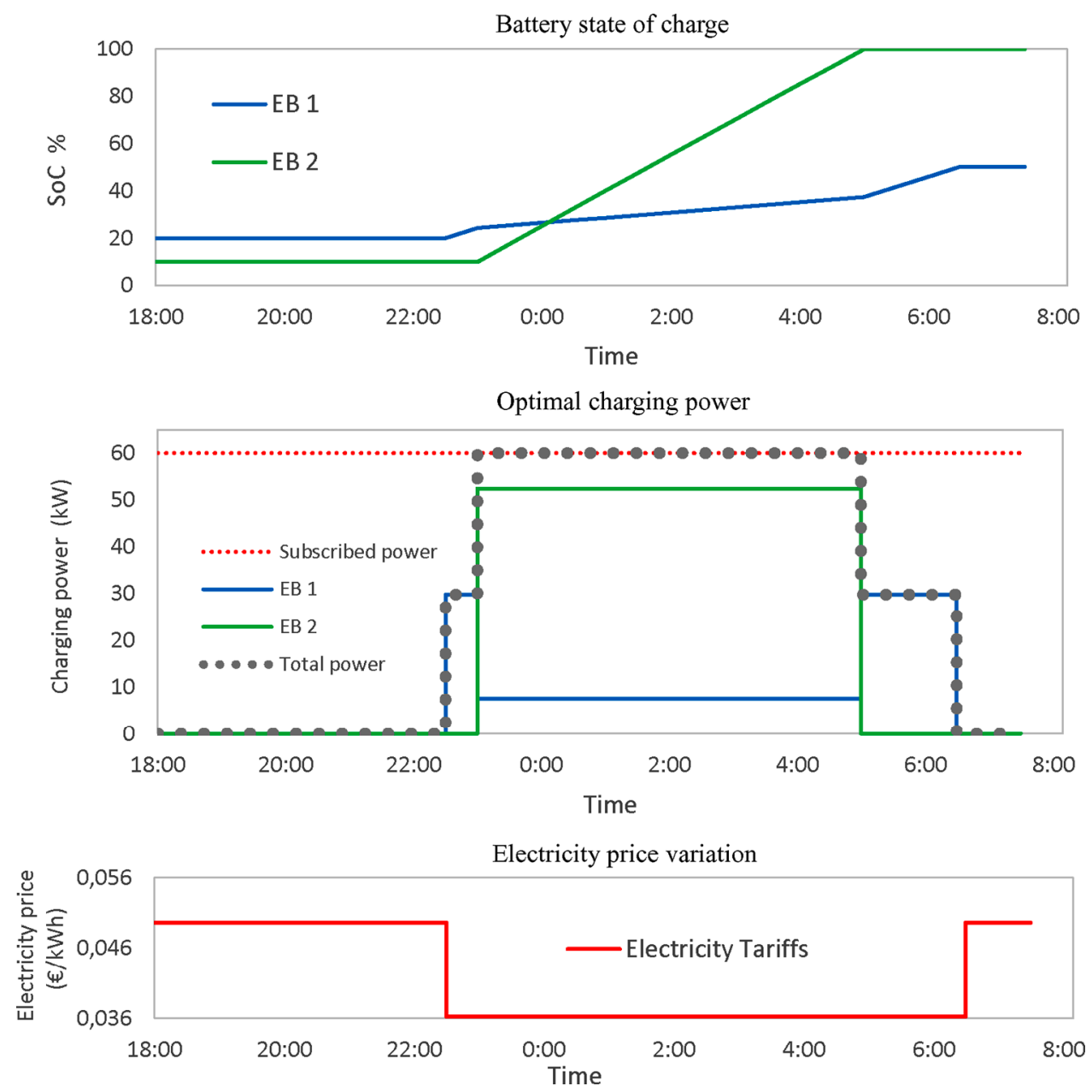

\subsection{Baseline comparison and annual cost review}

To illustrate the potential economic gain, we will compare a baseline situation to an optimised charge strategy. The baseline represents one typical behaviour by charging the EB with a maximum power of $60 \mathrm{~kW}$ as soon as possible, ignoring cost and maximum subscribed power, until it is fully charged.

We will use the same operating constraints as the scenario no. 3 excepting the number of the buses in the fleet that goes from 4 to 10 . The weighting factor was fixed to $(\alpha=0.7)$. The overshooting of subscribed power will be optionally charged at a rate of $0,060 € / \mathrm{kWh}$ as a penalty. The optimisation constraints results are shown respectively in Tables 9 and 10.

The optimisation parameters and constraints are shown in Table 8. 
Figure 11 Optimal charging schedules scenario 3 (see online version for colours)
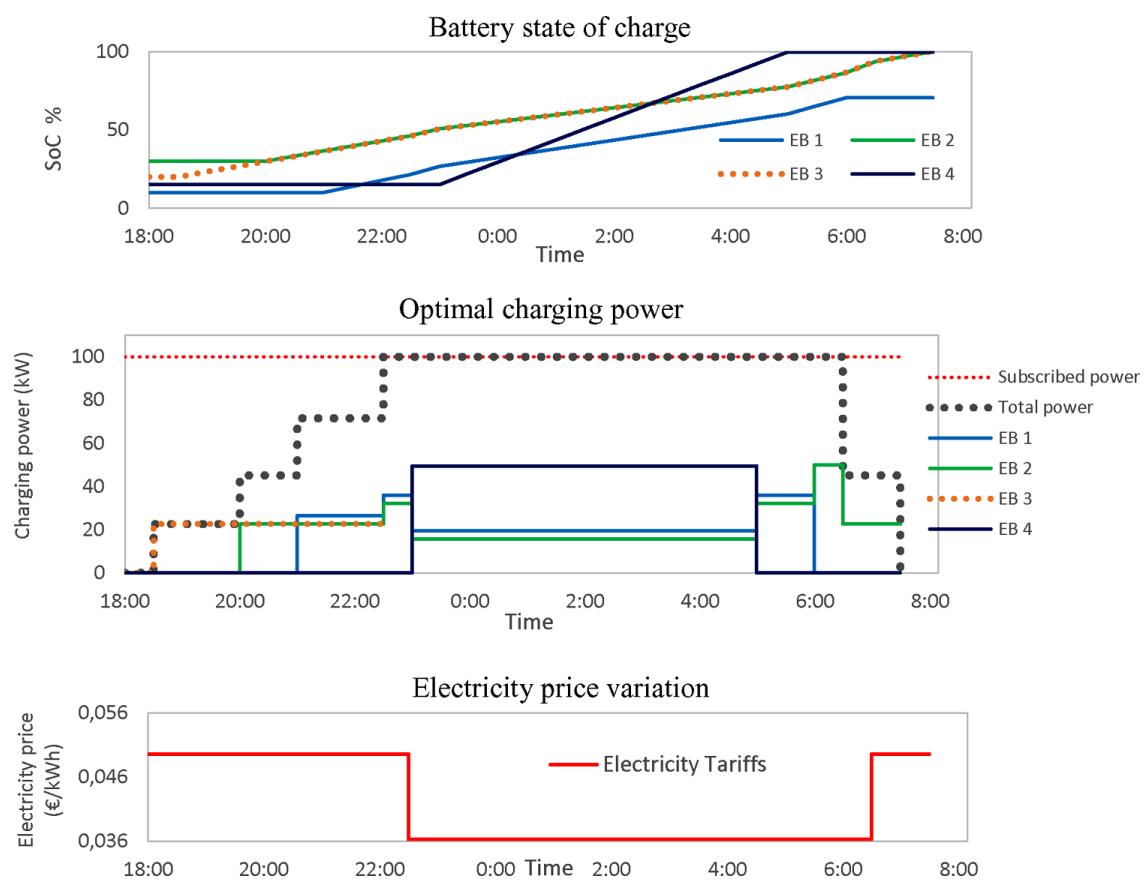

Table 8 Scenario 3: Optimisation constraints

\begin{tabular}{lcccc}
\hline & \multicolumn{4}{c}{ Number of bus fleet } \\
\cline { 2 - 5 } Smart charging & $E B 1$ & $E B 2$ & $E B 3$ & $E B 4$ \\
\hline Initial SoC & $10 \%$ & $30 \%$ & $20 \%$ & $15 \%$ \\
Arrival time & $21: 00$ & $20: 00$ & $18: 30$ & $23: 00$ \\
Departure time & $06: 00$ & $07: 30$ & $07: 30$ & $05: 00$ \\
Length of the trip & $100 \mathrm{~km}$ & $200 \mathrm{~km}$ & $200 \mathrm{~km}$ & $200 \mathrm{~km}$ \\
Target SoC & $70 \%$ & $100 \%$ & $100 \%$ & $100 \%$ \\
Maximum charging power per bus & $60 \mathrm{~kW}$ & $60 \mathrm{~kW}$ & $60 \mathrm{~kW}$ & $60 \mathrm{~kW}$ \\
Subscribed power (total maximum power) & \multicolumn{4}{c}{$100 \mathrm{~kW}$} \\
\hline
\end{tabular}

Table 9 Scenario 4: optimisation constraints

\begin{tabular}{lccccc}
\hline & \multicolumn{5}{c}{ Number of bus fleet } \\
\cline { 2 - 6 } Smart charging & $E B 1-2$ & $E B$ 3-4 & $E B ~ 5-6$ & $E B ~ 7-8$ & $E B$ 9-10 \\
\hline Initial SoC & $10 \%$ & $30 \%$ & $20 \%$ & $15 \%$ & $10 \%$ \\
Arrival time & $21: 00$ & $20: 00$ & $18: 30$ & $23: 00$ & $18: 00$ \\
Departure time & $06: 00$ & $07: 30$ & $07: 30$ & $05: 00$ & $07: 30$ \\
Length of the trip & $100 \mathrm{~km}$ & $200 \mathrm{~km}$ & $200 \mathrm{~km}$ & $200 \mathrm{~km}$ & $200 \mathrm{~km}$ \\
Target SoC & $70 \%$ & $100 \%$ & $100 \%$ & $100 \%$ & $100 \%$ \\
Maximum charging power per bus & $60 \mathrm{~kW}$ & $60 \mathrm{~kW}$ & $60 \mathrm{~kW}$ & $60 \mathrm{~kW}$ & $60 \mathrm{~kW}$ \\
Subscribed power (total maximum & \multicolumn{7}{c}{$300 \mathrm{~kW}$} \\
power) & \multicolumn{7}{c}{} \\
\hline
\end{tabular}


Table 10 Scenario 4: optimisation parameters and results

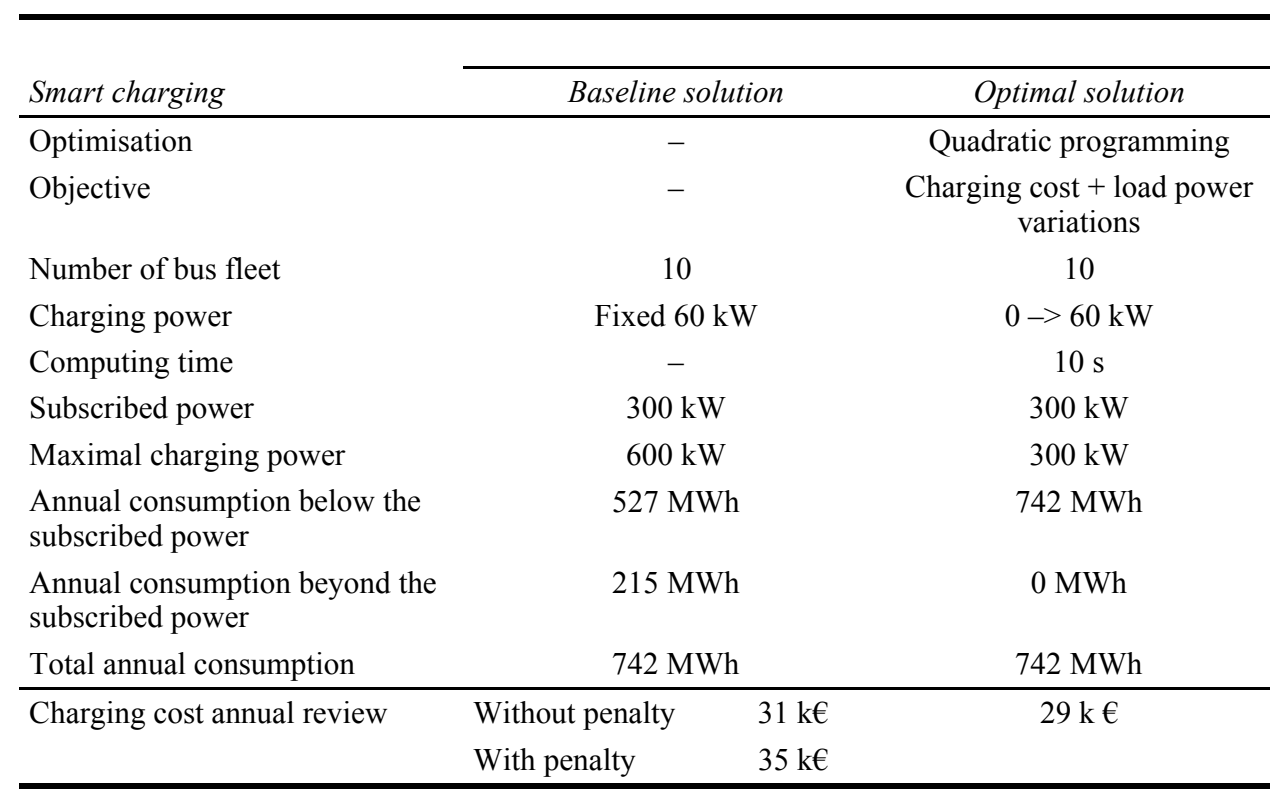

The results of quadratic optimisation in Table 10 and Figure 12 show that the optimal solution reduces the charging cost significantly with only $10 \mathrm{~s}$ of computing time. The optimal solution has been able to achieve a $6 \%$ reduction in the annual charging cost compared to the baseline solution and 17\% compared to the baseline solution + the over-limit charges if we consider that the overshooting of subscribed power is charged at a rate of $0.060 € / \mathrm{kWh}$.

Figure 12 Optimal charging schedules scenario No. 4 (see online version for colours)

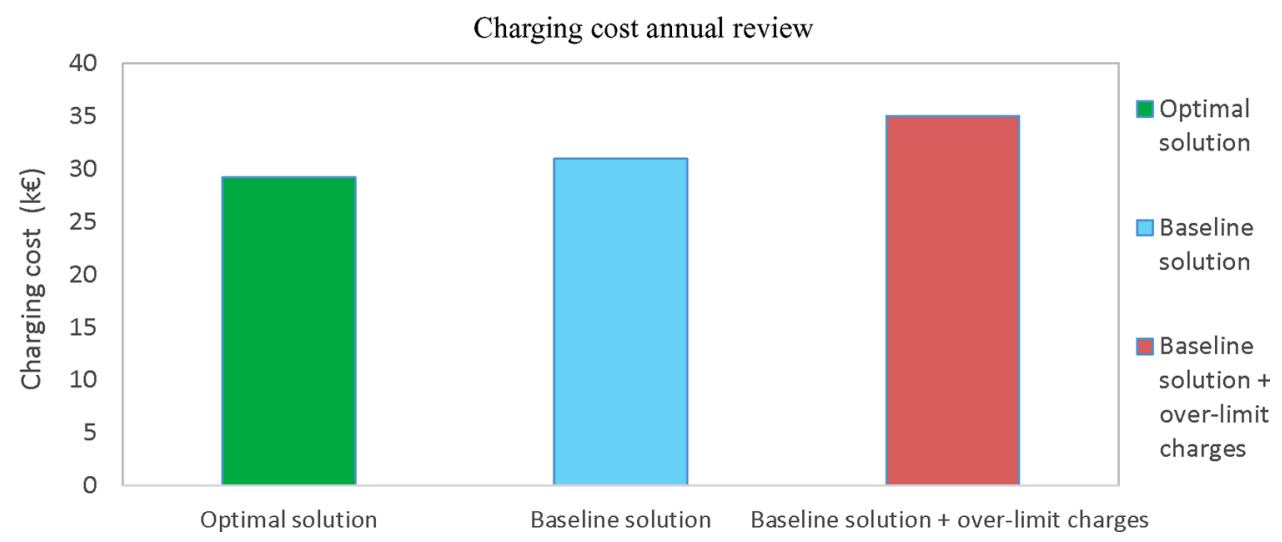

\section{Conclusion and future works}

This paper introduces an optimal charging strategy based on charging schedule planning and modulation of charging power for a fleet of electrical-powered buses. A case study 
has been implemented to illustrate the smart charging of an electric bus fleet during the night at the bus depot. The first results showed a coherent behaviour of the algorithm and a short computational time that makes possible to deal with large fleet of several hundreds buses.

In future work, we would like to extend the method in order to perform a conjoint optimisation of the cost together with the battery lifetime. Actually, the calendar ageing mechanisms require paying attention to the moments of the charge in relation to temperature and $\mathrm{SoC}$ of the batteries.

The end of the charging process has also to be carefully studied, in particular the $\mathrm{CV}$ phase that could have an impact on the time slots needed for a full recharge. Finally, a comparison between different methods that allow a multi objective optimisation will be necessary to achieve an acceptable trade-off between the optimum quality and the computational time.

\section{References}

Clement-Nyns, K., Haesen, E. and Driesen, J. (2010) 'The impact of charging plug-in hybrid electric vehicles on a residential distribution grid', IEEE Trans. Power Syst., Vol. 25, No. 1, pp.371-380.

Di Giorgio, A., Liberati, F. and Canale, S. (2014) 'Electric vehicles charging control in a smart grid: a model predictive control approach', Control Eng. Pract., Vol. 22, pp.147-162.

Dietmannsberger, M. (2017) 'Modelling the electrification of bus depots using real data: consequences for the distribution grid and operational requirements', 1st E-Mobility Power System Integration Symposium, Berlin, Germany, p.8.

Eddahech, A., Briat, O. and Vinassa, J-M. (2014) 'Determination of lithium-ion battery state-ofhealth based on constant-voltage charge phase', J. Power Sources, Vol. 258, pp.218-227.

European Commission (2018) Climate Action Policies. Roadmap for Moving to a Low-Carbon Economy, [online] https://www.ec.europa.eu/clima/policies/strategies/2050_en/ (Accessed 21 September, 2018).

Genovese, A., Ortenzi, F. and Villante, C. (2015) 'On the energy efficiency of quick DC vehicle battery charging', World Electric Vehicle Journal, Vol. 7, pp.570-576.

$\mathrm{Hu}$, J., Morais, H., Sousa, T. and Lind, M. (2016) 'Electric vehicle fleet management in smart grids: a review of services, optimization and control aspects', Renewable and Sustainable Energy Reviews, Vol. 56, pp.1207-1226.

International Electrotechnical Commission (2017) Electric Vehicle Conductive Charging System Part 1: General Requirements, Geneva, Switzerland.

Lam, L., Bauer, P. and Kelder, E. (2011) 'A practical circuit-based model for Li-ion battery cells in electric vehicle applications', IEEE 33rd International Telecommunications Energy Conference (INTELEC), Amsterdam, The Netherlands, pp.1-9.

Lewandowski, C., Groning, S., Schmutzler, J. and Wietfeld, C. (2012) 'Interference analyses of electric vehicle charging using PLC on the control pilot', IEEE International Symposium on Power Line Communications and Its Applications, Beijing, China, pp.350-355.

Mouli, G.R. C., Kaptein, J., Bauer, P. and Zeman, M. (2016) 'Implementation of dynamic charging and $\mathrm{V} 2 \mathrm{G}$ using Chademo and $\mathrm{CCS} /$ Combo DC charging standard', IEEE Transportation Electrification Conference and Expo (ITEC), Dearborn, MI, USA, pp.1-6.

Mousavi, G.S.M. and Nikdel, M. (2014) 'Various battery models for various simulation studies and applications', Renew. Sustain. Energy Rev., Vol. 32, pp.477-485.

Redondo-Iglesias, E., Venet, P. and Pelissier, S. (2018) 'Global model for self-discharge and capacity fade in lithium-Ion batteries based on the generalized eyring relationship', IEEE Trans. Veh. Technol., Vol. 67, pp.104-113. 
Soares, J., Sousa, T., Morais, H., Vale, Z., Canizes, B. and Silva, A. (2013) 'Application-specific modified particle swarm optimization for energy resource scheduling considering vehicle-to-grid', Appl. Soft Comput., Vol. 13, No. 11, pp.4264-4280.

Sousa, T., Morais, H., Soares, H. and Vale, Z. (2012) 'Day-ahead resource scheduling in smart grids considering vehicle-to-Grid and network constraints', Appl. Energy, Vol. 96, pp.183-193.

Sousa, T., Vale, Z., Carvalho, J.P., Pinto, T. and Morais, H. (2014) 'A hybrid simulated annealing approach to handle energy resource management considering an intensive use of electric vehicles', Energy, Vol. 67, pp.81-96.

Sundstrom, O. and Binding, C. (2012) 'Flexible charging optimization for electric vehicles considering distribution grid constraints', IEEE Trans. Smart Grid, Vol. 3, No. 1, pp.26-37.

Trigui, R., Jeanneret, B. and Badin, F. (2004) 'Systemic modelling of hybrid vehicles in order to predict dynamic performance and energy consumption building the VEHLIB library of models', RTS, Vol. 21, pp.129-150.

\section{List of abbreviations}

\begin{tabular}{ll}
\hline EV & Electric vehicle \\
EB & Electric bus \\
GHG & Greenhouse gas \\
SoC & State of charge \\
OCV & Open-circuit voltage \\
BMS & Battery management system \\
LP & Linear programming \\
QP & Quadratic programming \\
CCS & Combined charging system \\
PLC & Protocol line communication \\
EVSE & Electric vehicle supply equipment \\
\hline
\end{tabular}

